\title{
Relação entre Ciclo de Vida do Produto Turístico e Estratégias de Cooperação na Faixa Litorânea Urbana do Município de Natal
}

\author{
Relationship Between the Tourism Product Life Cycle and Co-operation Strategies in the \\ Urban Coastal Range of Natal
}

Anette Santiago Pereira ${ }^{1}$

Fernando Dias Lopes ${ }^{2}$

\begin{abstract}
Resumo
Com a concretização das ações estruturantes para o turismo em Natal, se expandem as ações baseadas na cooperação e a formalização de instâncias de governança. Este estudo teve como objetivo analisar a relação entre o ciclo de vida do produto turístico 'Litoral Urbano de Natal' e as estratégias de cooperação em uma perspectiva histórica. A teoria está constituída de uma revisão sobre ciclo de vida, ecologia populacional, sistema de turismo, estratégias de cooperação e novas formas de gestão. Os resultados apontaram que o gráfico do ciclo de vida do produto 'Litoral Urbano de Natal', encontra-se migrando de uma fase de crescimento para uma fase de maturidade. As estratégias de cooperação identificadas foram o consórcio, estratégia coletiva e aglomerados, que se relacionam ao ciclo de vida do Produto Turístico através do alcance da eficiência coletiva.
\end{abstract}

Palavras-chave: turismo; ciclo de vida do produto; cooperação.

\section{Abstract}

With the completion of tourism structuring actions, it was spread actions based on cooperation and formalization of governance institutions. This study aimed to examine the relationship between the tourism product life cycle 'Coastal Range of Natal" and the cooperation strategies in a historical perspective. The theoretical support is a revision about Resort Life Cycle, Theory of Population Ecology, System of Tourism, Co-operation Strategies and Management New Forms. Results showed that the life cycle graph of product 'Coastal Range of Natal' is moving from one stage of growth to a stage of maturity. The co-operation strategies identified were consortium, collective strategy and clusters, which are related to the life cycle of the tourism product 'Coastal Range of Natal' when the efficiency of collective actions is achieved.

Keywords: tourism; product life cycle; co-operation.

\footnotetext{
${ }^{1}$ Mestre em Administração; Professora Assistente do Curso de Turismo da UFPI (Universidade Federal do Piauí). E-mail: anesanti@hotmail.com

2 Doutor em Administração; Professor Adjunto do PPGA-UFRGS (Programa de Pós-Graduação em Administração da Universidade Federal do Rio Grande do Sul). E-mail: fdlopes@ea.ufrgs.br
} 


\section{Introdução}

A atividade turística passa a ser vista como novo segmento produtivo e a se projetar como alternativa econômica de desenvolvimento, sobretudo em países emergentes, como o Brasil. Neste país, isso ocorre a partir da década de 60 tendo como marco o decreto 55/1966. (CRUZ, 2001).

A atividade passa a fazer parte de um discurso que envolve questões voltadas principalmente à economia, tal como o desemprego, e de forma secundária a problemas sociais como a má distribuição de renda.

Baseados neste discurso, diversos investimentos foram realizados pelo governo federal com o intuito de fomentar a atividade, por meio de programas de estruturação do território, como, por exemplo, a Política de Mega Projetos Turísticos e o Programa de Desenvolvimento do Turismo - PRODETUR.

Com o intuito de dar continuidade e suprir as deficiências desses programas, novas políticas foram criadas, em meados dos anos 2000, dentre elas os Pólos de Desenvolvimento Sustentável do Turismo, através de projetos e ações voltados ao fortalecimento dos elos da cadeia produtiva, como por exemplo, a criação do Pólo Costa das Dunas no Rio Grande do Norte em 2005.

A partir destes a cooperação estratégica passa a se disseminar pelo país como forma de gestão democrática do turismo, envolvendo empresários, governo e terceiro setor para fortalecimento e controle da atividade.

Neste aspecto, a Cidade de Natal tem se apresentado como um produto turístico de destacada expressividade no cenário nacional, sendo composto de diversos elementos e subprodutos. Dentre esses elementos está o seu litoral urbano, lócus onde a atividade turística se consolida no destino.

Alguns componentes desse produto turístico têm enfrentado problemas relativos ao seu consumo sem controle que culminaram em impactos sociais, econômicos, ambientais e que podem comprometer o macro produto turístico da cidade do Natal.

Dessa forma, tendo como referência os conceitos de ciclo de vida do produto turístico e as mudanças estruturais percebidas na forma de gestão locais, através das parcerias e novas 
formas ou estratégias de trabalho cooperado, o presente trabalho se propõe a responder a seguinte questão de pesquisa: Qual a relação entre o ciclo de vida do produto turístico "Litoral Urbano de Natal" e estratégias de cooperação em uma perspectiva histórica?

A abordagem metodológica utilizada foi uma pesquisa descritiva, causal e estudo de caso. Os dados foram coletados por meio de entrevistas semi-estruturadas e dados secundários por meio de consulta a documentos institucionais de indicadores básicos de turismo do Rio Grande do Norte, da Secretaria Estadual de Turismo do Rio Grande do Norte. Foram utilizadas abordagens metodológicas quantitativa e qualitativa. Os sujeitos entrevistados, quanto à abordagem qualitativa, foram os agentes atuantes na concepção e implementação dos projetos de desenvolvimento do turismo no 'Litoral Urbano de Natal', sendo 14 instituições entrevistadas - sendo quatro representantes do setor público, sete da iniciativa privada e três do terceiro setor. Destas, um entrevistado foi representante de três instituições, razão pela qual a pesquisa foi consolidada por meio de 12 respondentes.

Os dados utilizados na abordagem quantitativa compreenderam o número de visitantes que definiu o ciclo de vida do produto "Litoral Urbano de Natal". Seu universo compreendeu os dados relativos ao período de 1960 a 2007, mas em função de ausência de dados foram mantidas as variáveis válidas, que corresponderam ao período de 1991 a 2007.

\section{Ecologia Populacional e Sistema de Turismo (Sistur): Concepções Teóricas do Pensamento Sistêmico}

A ecologia populacional é uma proposição teórica que enfatiza processos de seleção ambiental. Os ecólogos populacionais tentam explicar como condições políticas, sociais e econômicas afetam a abundância e diversidade de organizações, tentando justificar a característica de mutação das organizações ao longo do tempo.

Os estudos em abordagens ecológicas estão voltados para a criação de novas organizações e o desaparecimento de outras, em oposição a abordagens de adaptação que explicam as mudanças na diversidade organizacional em termos de escolhas estratégicas e mudanças nas organizações existentes. Para tal, a exemplo do estudo de Baum (1999), são propostos dois modelos de análise. O primeiro com um foco em taxas de fundação e fracasso organizacional, e o segundo com um foco nos processos de mudança nas populações organizacionais. 
O modelo com foco em taxas de fundação e fracasso organizacional na perspectiva da ecologia organizacional representa variações em relação a abordagens tradicionais que focam iniciativas, capacidades e habilidades individuais. No que diz respeito à abordagem para mudança organizacional, estas refletem a atuação de quatro processos: variação, seleção, retenção e competição. (HANNAN; FREEMAN, 1989).

As pesquisas de abordagens ecológicas tanto no que diz respeito aos processos demográficos, ecológicos ou tecnológicos fazem referência à sobrevivência da organização ao longo do tempo (BAUM, 1999).

Neste sentido, as referidas reflexões abordam o fator sobrevivência e fracasso das organizações, pressupondo que as mesmas possuem um tempo de sobrevivência desde a sua fundação até o seu fracasso na seleção ambiental, apresentando um dado ciclo de vida. As posições competitivas das organizações também remetem a taxas de sobrevivência e fracasso organizacional, pressupondo um ciclo de vida para a organização.

Mauad (2005) esclarece que os pesquisadores não tratam na análise a fase final de declínio ou envelhecimento e sim instituem crises ao longo das fases de evolução das organizações. Neste sentido, o sucesso ou fracasso da organização está relacionado à sua capacidade de enfrentar os desafios que aparecem nos diferentes estágios de seu ciclo. Esta idéia reflete a vertente de adaptação das organizações ao ambiente.

Assim, a teoria da ecologia populacional oferece uma série de argumentos e pressupostos teóricos que favorecem traçar uma metodologia em conjunto com o pensamento sistêmico para direcionar estudos na área de turismo, em especial os voltados à análise do ciclo de vida dos produtos.

Auxiliando o desenvolvimento desta abordagem Beni (2001) apresenta o Sistema de Turismo como uma alternativa metodológica de entender estrutura da atividade turística para fins de estudo. 


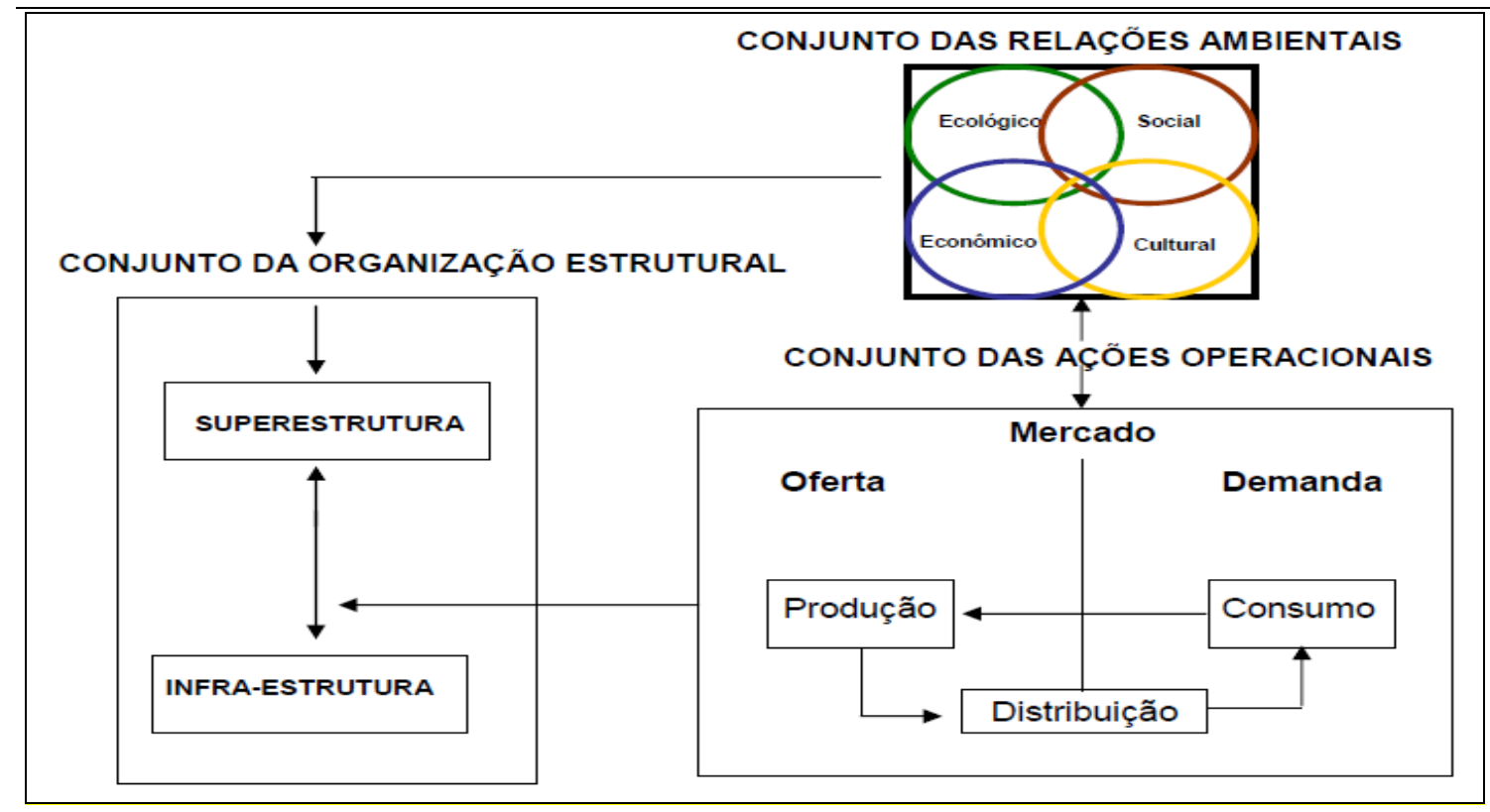

Figura 1 - O Sistema de Turismo, modelo referencial.

Fonte: Beni, 2001. p. 48.

Nesta estrutura estão explícitas as variáveis que influenciam no ciclo de vida dos produtos turísticos, as quais são denominadas de subconjuntos e que estão embutidas nos três grandes conjuntos dispostos: Relações ambientais; Organização estrutural e Ações operacionais.

Estudar o ciclo de vida dos produtos turísticos envolve traçar uma metodologia que permita de maneira organizada apresentar as variáveis que implicam na mudança entre as fases do ciclo. Apesar disso, Butler (1980) defende que não existem fatores exatos que definam a passagem de um estágio para o outro.

O referido autor propõe uma evolução baseada em cinco fases distintas: exploração, envolvimento, desenvolvimento, consolidação, estagnação. Além destas, o seu modelo pode evoluir para o declínio e/ou rejuvenescimento.

Beni (2001) também apresenta um modelo de ciclo de vida da atividade turística, entretanto, voltado a uma abordagem do marketing do destino. Para isso ele apresenta uma matriz de estratégia de marketing e as fases do ciclo de vida de um produto. Em sua concepção este ciclo é composto por cinco fases que estão relacionadas a quatro estratégias de marketing. 
Lundtorp e Wanhill (2001) em sua discussão teórica argumentam que é possível explicar como fatores locais causam divergência da teoria. Decisões políticas e comerciais, do ponto de vista dos fornecedores são capazes de interromper o caminho de crescimento do ciclo. Diferentes decisões entre organizações públicas e privadas são importantes para a velocidade, forma e processo do ciclo de vida. Além disso, propõem que existem quatro questões políticas de importância para as destinações: regulamentação, investimento público, desenvolvimento de parcerias e incentivos financeiros.

Neste sentido, percebem-se algumas semelhanças no que se refere aos esclarecimentos dos autores Mauad (2005) e Lundtorp e Wanhill (2001). Ambos apresentam que fatores externos podem interferir no desenvolvimento do ciclo. Outra semelhança diz respeito às crises instituídas ao longo das fases de evolução do ciclo, que na visão dos autores se confirmam.

Nesta pesquisa assumiu-se um modelo de ciclo de vida baseado em quatro fases, introdução, desenvolvimento, maturidade e declínio. Estas fases foram relacionadas a quatro períodos históricos identificados como representativos para o Produto 'Litoral Urbano de Natal' em análise: PA: 1960 a 1982, PB: 1983 a 1990, PC: 1991 a 2002, PD: 2003 a 2007.

Esses períodos foram pré-determinados a partir do levantamento dos marcos históricos do turismo na Cidade de Natal, e levando em consideração o histórico do turismo em âmbito Nacional. O primeiro período PA (1960 a 1982) teve como marco o decreto-lei 55/1966 em âmbito nacional e a Construção do Hotel Reis Magos na Cidade. O Segundo Período PB (1983 a 1990) está relacionado à inauguração da Via-Costeira (1983) e se estende até 1990, com o término do governo Collor. O terceiro período PC (1991 a 2002) se baseia nas Políticas de turismo instituídas durante os governos nacionais de Itamar Franco e Fernando Henrique. E, o quarto período PD (2003 a 2007) trata das ações implementadas durante o governo Lula.

A escolha dos períodos se deu em concordância com realidade nacional, por duas razões. Em primeiro lugar as políticas e ações implementadas na Região Nordeste e em Natal obedeceram às políticas e macro programas de incentivo implementados pelo Governo Federal. E Por fim, a responsabilidade sobre a implementação de políticas e obras de desenvolvimento do turismo em Natal, estão historicamente concentradas no Poder Público Estadual, cujos anos de eleições coincidem com os da Instância Federal. 


\section{Estratégias de Cooperação e Novas Formas de Gestão}

Mintzberg, Ahlstrand e Lampel (2000) ilustram que a palavra estratégia existe há bastante tempo e que grande parte dos livros-texto que discutem sobre estratégia a consideram como planos elaborados pela alta administração que visam atingir resultados consistentes com as missões e os objetivos das organizações. Embora não estabeleça críticas a este conceito específico, elucida que o conceito de estratégia requer uma série de definições, que demonstrem a complexidade do termo.

Dentre os principais temas trabalhados Mintzberg, Ahlstrand e Lampel (2000) apresentam alguns assuntos estabelecidos nessa formulação cooperativa de estratégia, sugerindo dentre os seus vários elementos a concepção de:

a) Estratégia coletiva: onde as organizações precisam desenvolver estratégias no nível coletivo para atuarem com as complexas interdependências;

b) Alianças estratégicas: variedade de diferentes arranjos cooperativos, normalmente entre fornecedores e clientes como parceiros.

c) Terceirização estratégica: buscar contratação externamente quando os fornecedores tem maiores vantagens comparativas.

No que concerne à cooperação, muitos têm sido os motivos que levam firmas a desenvolverem trabalhos conjuntos. Na visão de Contractor e Lorange (1988) tanto a competição quanto a cooperação provêem simultâneos caminhos para o sucesso.

Kogut (1988) apresenta três perspectivas teóricas para explicar a formação de negócios conjuntos (joint-ventures). A primeira delas está baseada na Teoria dos custos de transação, considerando que a minimização dos custos seria motivadora de qualquer empreendimento. A segunda abordagem refere-se às teorias de comportamento estratégico, as quais consideram a maximização dos lucros por meio do aumento da competitividade da empresa, portanto os melhores parceiros seriam os que trouxessem maiores vantagens competitivas. Por fim, considera os negócios conjuntos como oportunidade de transferência de conhecimento e de aprendizado organizacional.

Lorange e Ross (1996) sugerem uma estrutura formada por quatro modelos de alianças baseados na disponibilidade de recursos: 
a) Acordo Provisório: quando se estabelece um contrato por tempo determinado. Geralmente as empresas-mãe colocam um mínimo de recurso esperando a complementação uma da outra e este é totalmente recuperado por elas;

b) Consórcio: trata-se da junção de forças de diferentes empresas ou organizações visando a um objetivo comum, como por exemplo, para valorização de um produto ou marca, e pode envolver a formalização de um órgão, de normas disciplinares e técnicas e etc. Geralmente as partes estão dispostas a alocar mais recursos e os valores gerados dentro da aliança são distribuídos entre as sócias;

c) Joint-venture baseada em projeto: situação na qual as empresas colocam um mínimo de recursos entrando em acordo para criá-los em conjunto. Os recursos gerados não são distribuídos entre as partes, exceto resultados financeiros;

d) Joint-venture plena: As empresas colocam recursos em abundância e permitem que os recursos gerados sejam mantidos na aliança. Pode ser caracterizado como criação de uma entidade organizacional mais ou menos autônoma e com vida estratégica própria.

É importante perceber que até o presente momento discutiu-se o tipo de alianças entre empresas, cabendo agora abordar as parcerias entre as mesmas, governo e comunidades locais, focalizando as suas relações.

No caso da atividade turística, essas ações por meio de articulações micro-regionais têm sido alavancadas através dos conselhos existentes em cada município, os quais contam com os diversos representantes das bases locais, sejam empresários ou moradores e ainda dos Pólos de Turismo.

A discussão sobre novas formas de gestão da atividade turística ganhou força nos últimos anos, sobretudo tendo como base as políticas do governo federal de desenvolvimento com foco em arranjos de produção e formação de pólos de turismo. Esta idéia está pautada no aumento da competição por meio da cooperação entre empresas.

Por fim, ao se resgatar o conceito de eficiência coletiva pode-se entender a virtude dos pólos. Schmitz (1997) traz nesse aspecto a noção de eficiência coletiva. O conceito de eficiência coletiva aborda a noção de que a viabilidade econômica não pode ser compreendida com foco em firmas individuais. Define-a como a vantagem competitiva derivada de economias externas locais e ação conjunta. 
O autor esclarece que o cluster refere-se a uma concentração setorial e geográfica de firmas, o que não garante necessariamente a existência de eficiência coletiva.

Isso pode ser confirmado por Garrido (2001) quando discute que os clusters surgem de um processo endógeno, espontâneo e por antecedentes culturais e históricos locais, auxiliados pela existência de tradição local em ações integradas. Apesar disso, existe um consenso de que o Estado tem um importante papel no apoio e fortalecimento das bases locais.

$\mathrm{Na}$ sua visão o entendimento desse conceito passa pela concepção de desenvolvimento regional, o qual pode ser explicado sobre a ótica de duas correntes principais. A primeira relaciona-se ao planejamento centralizado de um Estado nacional "de cima para baixo", em que o Estado é o indutor dos grandes projetos estruturantes. A segunda é conhecida como desenvolvimento endógeno ou local cujo movimento se coordena "de baixo para cima". Esta se estabelece através do Sistema Produtivo local fazendo uso das potencialidades sócioeconômicas intrínsecas. Os atores locais são capazes de se estruturarem e se mobilizarem fazendo o uso de suas características culturais, como por exemplo, o seu capital humano.

Embora o conceito de eficiência coletiva tenha sido trabalhado na concepção de clusters ele também pode ser utilizado para avaliar outros conjuntos de relações. Para que a eficiência coletiva possa ser avaliada, alguns vetores de sinergia devem ser identificados. Lins (2000) cita como vetores de sinergia: interações diversas, parcerias público-privadas, envolvendo oferta de serviços e infraestrutura e cooperação fornecedor-cliente. Para este autor, as interrelações assumem diferentes formas: Vínculos verticais - para trás (fornecedores, subcontratados) e para frente (compradores, trade); Vínculos horizontais - inclui marketing, conjunto de produtos, aquisições coletivas de insumos e utilização comum de instalações, máquinas e equipamentos especializados; e, Vínculos multi-laterais - envolvendo produtores locais, as associações empresariais e a administração pública local. Lins (2000) defende que os seus efeitos podem ser estáticos, repercutindo em termos de ganhos de eficiência, e dinâmicos por meio de progresso tecnológico e de crescimento. Estes quando combinados trazem uma maior rapidez na inovação incrementando a competitividade e melhoria de crescimento. 


\section{Análise dos Resultados}

\subsection{Ciclo de vida do produto 'Litoral Urbano de Natal' e análise das curvas de tendência}

Para dar início ao processo de análise do ciclo de vida do produto 'Litoral Urbano de Natal' foram definidas as variáveis que deveriam compor o gráfico. Seguindo os preceitos de Butler (1980) o gráfico do ciclo de vida corresponde à relação número de passageiros versus tempo de análise.

O período proposto para análise nesta pesquisa corresponde de 1960 a 2007 . Uma vez que os dados referentes ao número de turistas somente começou a ser coletado de maneira sistematizada a partir de 1991, o período de 1960 a 1990 não foi representado na análise gráfica.

Portanto, em função da inexistência dos dados o Gráfico 1 apresenta o fluxo de turistas relativo aos anos de 1991 a 2007. O gráfico foi representado pela variável 'Tempo' no eixo ' $x$ ', e 'fluxo de turistas' no eixo ' $y$ '.

Foi possível perceber no período em análise que o gráfico apresenta uma tendência primária ascendente, com movimentos secundários de instabilidade ao longo de seu ciclo e uma leve tendência de queda ao final do gráfico.

Gráfico 1 - Relação fluxo de turistas em Natal versus período de análise

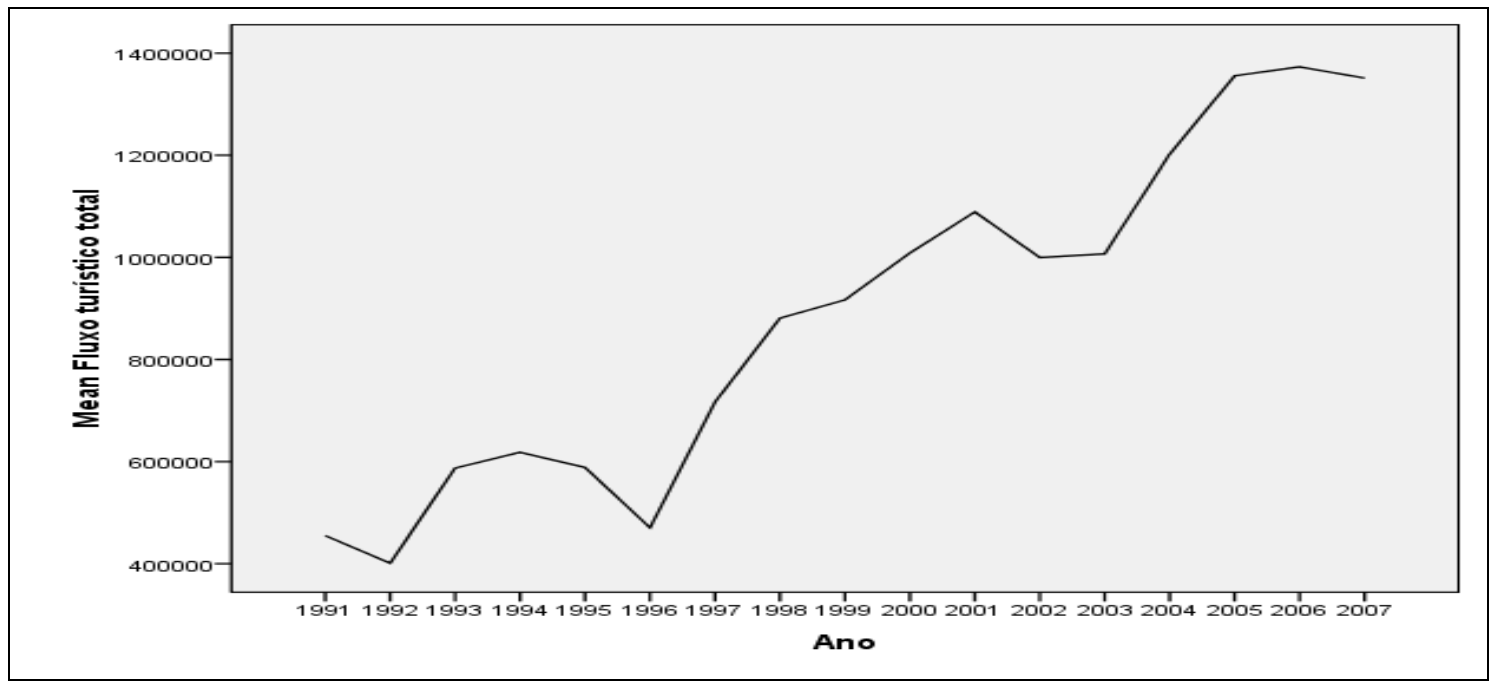

Fonte: Dados da pesquisa, 2009. 
Essa tendência de queda permite que duas hipóteses sejam levantadas. Seguindo-se a abordagem de Mauad (2005) e de Lundtorp e Wanhill (2001) a primeira hipótese sugere a existência de crises que se instituem ao longo do ciclo de vida do produto. Nesta vertente, a tendência de queda que se apresenta ao final da curva trata-se de uma crise que se institui na atividade turística, cuja solução possibilitará que a linha do gráfico permaneça ascendente. A segunda hipótese, voltada para a vertente proposta por Butler (1980), sugere que o movimento ao final da curva trata-se da passagem entre fases do ciclo.

Embora esta pesquisa não apresente um instrumento que permita confirmar as hipóteses, a análise da curva de tendência permite uma aproximação do modelo de Butler (1980). A curva de tendência foi testada fazendo uso dos dados válidos, 1991 a 2007.

Os dados referentes ao número de passageiros foram testados em funções não lineares. É relevante esclarecer que foram testadas quatro distintas funções: a função quadrática - dada pela equação $\mathrm{x}^{2}+\mathrm{x}+\mathrm{a}$; a função cúbica - dada pela equação $\mathrm{x}^{3}+\mathrm{x}^{2}+\mathrm{x}+\mathrm{a}$; a função exponencial - dada pela equação $\mathrm{a}^{\mathrm{x}}$; e, a função inversa - dada pela equação $1 / \mathrm{X}$.

Os gráficos foram analisados na perspectiva do ajustamento, modelagem e da previsibilidade. $\mathrm{O}$ ajustamento corresponde ao valor do $\mathrm{R}^{2}$ ajustado. Quanto mais próximo o $\mathrm{R}^{2}$ estiver de 1 maior o seu poder explicativo da evolução dos dados. A modelagem é definida pela função que melhor se ajusta aos dados. É avaliada quanto à significância de seus coeficientes. Quanto mais próximos os coeficientes estiverem de 0 , mais significantes serão. A literatura aceita que a significância pode ser mensurada a $1 \%$ e a $5 \%$. Por fim, a previsibilidade corresponde à análise da disposição gráfica visual da curva de tendência. (HAIR et. al., 2005).

O Gráfico 2 apresenta um resumo gráfico comparativo das 4 funções analisadas. No que diz respeito ao ajustamento da curva, pode-se inferir que os modelos analisados que apresentaram o maior $\mathrm{R}^{2}$ ajustado foram as funções quadrática e cúbica.

A escolha dos períodos se deu em concordância com realidade nacional, por duas razões. Em primeiro lugar as políticas e ações implementadas na Região Nordeste e em Natal obedeceram às políticas e macro programas de incentivo implementados pelo Governo Federal. E Por fim, a responsabilidade sobre a implementação de políticas e obras de desenvolvimento do turismo em Natal, estão historicamente concentradas no Poder Público Estadual, cujos anos de eleições coincidem com os da Instância Federal. 
No que se refere à modelagem da função, os coeficientes que se mostraram mais significantes a $1 \%$ pertencem à função exponencial. Embora a $5 \%$ a constante da função exponencial e da função cúbica, e, os coeficientes da função quadrática foram também significativos. Quanto à previsão, a linha que melhor se ajustou visualmente ao gráfico foi a da função cúbica e a que menos se ajustou a da função inversa.

Gráfico 2 - Resumo gráfico comparativo das curvas de tendência

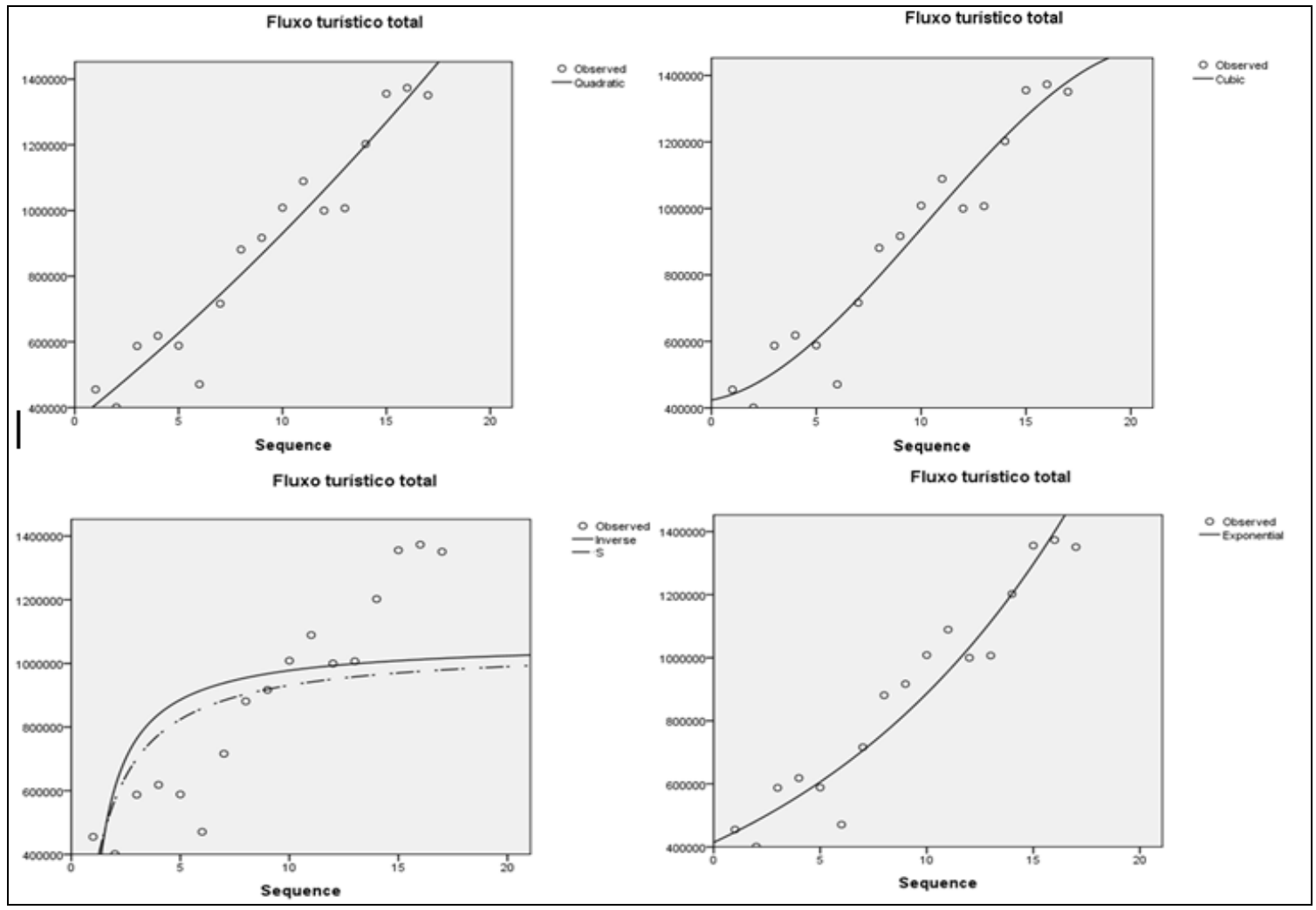

Fonte: Dados da Pesquisa, 2009

Neste aspecto, pode-se inferir, que no conjunto de maior $\mathrm{R}^{2}$ ajustado, significância de pelo menos um coeficiente ou constante, se analisados a 5\% e melhor previsão na demonstração gráfica, a função cúbica é a que melhor representa o ciclo de vida do produto 'Litoral Urbano de Natal'. 
Ao se comparar a curva de tendência da função cúbica ao gráfico do ciclo de vida do produto turístico apresentado por Butler (1980), pode-se inferir que a curva de tendência do gráfico representa a curva do ciclo de vida do produto turístico até a fase de estagnação proposta pelo autor, e, portanto, até a fase de Maturidade, conforme modelo proposto para a pesquisa.

\subsection{Da definição da fase do ciclo de vida do produto 'litoral urbano de Natal' no ano de} 2007.

A definição da fase atual do ciclo de vida do produto turístico em estudo se consolidou inicialmente por meio da análise realizada no subitem 4.1. desta pesquisa, que conclui que a curva da função cúbica melhor se adapta ao gráfico do ciclo.

Por esta razão foi elaborado o instrumento de pesquisa que relaciona as fases do ciclo aos períodos históricos pré-definidos. O Formulário respondido corresponde ao anexo $\mathrm{A}$ e o roteiro de entrevista ao anexo B.

Tanto formulário quanto roteiro de entrevista foram aplicados com os sujeitos entrevistados. Dos 12 respondentes, 11 efetuaram o preenchimento do formulário. O respondente que se recusou a responder o formulário explicou que acredita que o produto está em "queda", portanto em uma fase de declínio.

O formulário respondido foi analisado por meio da freqüência de respostas. A análise se deu a partir da Tabela 1.

Tabela 1 - Frequência de respostas dos entrevistados

\begin{tabular}{|l|l|l|l|l|}
\hline $\begin{array}{c}\text { PERÍODOS DE } \\
\text { DESENVOLVIMENTO }\end{array}$ & INTRODUÇÃo & CRESCIMENTO & MATURIDADE & DECLÍNIO \\
\hline Período A & 1 & 0 & 0 & 0 \\
\hline Período B & 36 & 11 & 5 & 16 \\
\hline Período C & 43 & 64 & 31 & 24 \\
\hline Período D & 34 & 67 & 70 & 55 \\
\hline
\end{tabular}

Fonte: Dados da Pesquisa, 2009 
A Tabela 1 permite uma análise tanto vertical quanto horizontal dos dados. Em uma análise horizontal da freqüência das respostas pode-se inferir que o Período A possui como representativa a fase de introdução do ciclo de vida do Produto, embora pouco representativa, pois consta a única freqüência de resposta. O Período B teve a maior freqüência de resposta (36) também na fase de introdução. O Período $C$ teve a sua maior freqüência de respostas (64) na fase de crescimento da atividade. O Período D apresentou a sua maior freqüência na fase de maturidade (70), embora com uma grande proximidade da fase de crescimento (67).

Em uma análise vertical da tabela, a freqüência de respostas permite inferir que a Fase de Introdução é mais representativa no Período C (43), a Fase de Crescimento é mais representativa do Período D (67), a Fase de Maturidade é mais representativa do Período D (70), e a Fase de Declínio é mais representativa do Período D (55).

Comparando-se a análise horizontal e vertical, os períodos de análise apresentam a seguinte configuração:

a) Período A: Fase de introdução (Frequência 1);

b) Período B: Fase de introdução (Frequência 36);

c) Período C: Fase de Crescimento (Frequência 64);

d) Período D: Fase de Maturidade (Frequência 70), Fase de Crescimento (Frequência 67) e Fase de declínio (Frequência 55).

Portanto, pode-se inferir que o Período A não teve grande representatividade para a análise de um ciclo de vida de quatro fases, pois apresentou por um único respondente uma freqüência de análise.

A pesquisa demonstrou que na percepção dos entrevistados, a atividade turística entra na fase de introdução no Período $\mathrm{B}$, após a construção da Via Costeira. O período C é representativo de uma fase de crescimento da atividade que evolui até o período D. O período D apresenta um processo de migração aparente da fase de crescimento para maturidade do Produto. Esta inferência pode ser comprovada por meio da freqüência de respostas - 67 para fase de crescimento, 70 para fase de maturidade e 55 para fase de declínio.

É, contudo, aparente que as ações estratégicas representativas da fase de declínio dispostas no formulário - da ação 44 à 56 - ocorrem nos períodos $\mathrm{B}, \mathrm{C}$ e $\mathrm{D}$, confirmando a vertente de 
Mauad (2005) de crises instituídas durante todo o ciclo da atividade. A pesquisa mostrou ainda que as crises foram superadas por meio de estratégias individuais e coletivas, adotadas tanto pelo poder público, iniciativa privada e terceiro setor, assim como na relação entre eles. Esta análise será realizada no capítulo 4.3 que se segue.

Por fim, pode-se concluir que o ano de 2007 encontra-se em um aparente processo de migração da fase de crescimento para maturidade do ciclo, embora com uma pequena tendência de que o ciclo tenha alcançado a fase de maturidade.

\subsection{Da análise das relações de cooperação entre os agentes}

Os agentes atuantes, identificados e entrevistados, foram categorizados nos três setores da sociedade. Neste sentido, as relações de cooperação identificadas foram organizadas seguindo a lógica institucional de participação no planejamento do turismo. Após a análise das entrevistas foi possível identificar a existência de relações nos seguintes grupos:

a) Grupo 1: Iniciativa Privada + Iniciativa Privada

b) Grupo 2: Iniciativa Privada + Poder Público

c) Grupo 3: Iniciativa Privada + Poder Público + Terceiro Setor

Foram identificadas as relações que se consolidaram durante o processo de desenvolvimento do produto turístico. Essas relações foram avaliadas quanto aos projetos que as compõem, grau de interdependência entre os agentes envolvidos, estrutura das inter-relações e quanto à razão para cooperar, conforme previsto no ensaio teórico.

No que concerne aos projetos que as compõem, foram identificados para o primeiro grupo as ações promocionais e ações operacionais/comerciais. Para o segundo grupo foram identificadas ações promocionais e projetos de infraestrutura (Via Costeira e PRODETUR/RN). E, para o terceiro grupo foram encontradas as instâncias de governança formais - Pólo Costa das Dunas e Conselho Estadual de Turismo.

A cooperação foi identificada nos três grupos de relações, embora não tenham sido percebidas nas ações operacionais/comerciais e na implantação da Via Costeira.

Quanto ao grau de interdependência (CONTRACTOR; LORANGE, 1988) pôde-se inferir que os agentes envolvidos tinham nas primeiras iniciativas uma maior dependência entre si, que diminui a medida que o produto se consolida no mercado. No que corresponde à estrutura de 
inter-relações (LINS, 2000) percebeu-se a existência de vínculos Verticais, horizontais e multilaterais. Apesar disso, nas ações de desenvolvimento em que foi diagnosticada a cooperação, estiveram presentes os vínculos horizontais e multi-laterais. Isto tem uma implicação na forma predominante da cooperação, pois implica na não ocorrência de alianças que envolvem a fusão ou aquisição de empresas turísticas, no destino. Apesar disso, é relevante esclarecer que o fato de não ter sido abordada nesta pesquisa não significa a sua inexistência.

Quanto às razões para cooperar (KOGUT, 1988) foram identificados o aumento da competitividade do destino, e conseqüentemente dos produtos que o compõe, e a troca de experiências e conhecimento para atuar no mercado internacional. Embora não tenha sido citado por Kogut (1988) os entrevistados apresentaram como razão para cooperar a evolução na concepção de atuação na atividade turística, em que a atividade somente pode atingir a eficiência por meio da ação coletiva.

No que diz respeito às estratégias de cooperação adotadas, as mesmas estão apresentadas no Quadro 1.

Quadro 1 - Estratégias identificadas versus categoria de relações versus Projetos de desenvolvimento do turismo.

\begin{tabular}{|c|c|c|}
\hline $\begin{array}{l}\text { ESTRATÉGIAS } \\
\text { DE } \\
\text { COOPERAÇÃO }\end{array}$ & $\begin{array}{l}\text { CATEGORIA DE GRUPO DE } \\
\text { RELAÇÕES }\end{array}$ & $\begin{array}{c}\text { PROJETOS DE } \\
\text { DESENVOLVIMENTO DO } \\
\text { TURISMO/AÇÕES } \\
\text { ESTRATÉGICAS } \\
\end{array}$ \\
\hline \multirow[t]{2}{*}{ Consórcio } & $\begin{array}{l}\text { Iniciativa } \text { Privada }+ \text { Iniciativa } \\
\text { Privada }\end{array}$ & Ações Promocionais \\
\hline & Iniciativa Privada + Poder Público & Ações Promocionais \\
\hline \multirow{4}{*}{ Estratégia Coletiva } & $\begin{array}{l}\text { Iniciativa } \\
\text { Privada }\end{array}$ & Ações Promocionais \\
\hline & \multirow{2}{*}{ Iniciativa Privada + Poder Público } & Ações Promocionais \\
\hline & & PRODETUR/RN \\
\hline & $\begin{array}{l}\text { Iniciativa Privada }+ \text { Poder Público }+ \\
\text { Terceiro Setor }\end{array}$ & Pólo Costa das Dunas \\
\hline \multirow{2}{*}{ Aglomerados } & $\begin{array}{llll}\begin{array}{l}\text { Iniciativa } \\
\text { Privada }\end{array} & \text { Privada }+ \text { Iniciativa } \\
\end{array}$ & Pólo da Via Costeira \\
\hline & $\begin{array}{l}\text { Iniciativa Privada + Poder Público + } \\
\text { Terceiro Setor }\end{array}$ & Pólo Costa das Dunas \\
\hline
\end{tabular}

Fonte: Dados da Pesquisa, 2009 
4.5. Da influência das estratégias de cooperação para o atual estágio de desenvolvimento do produto turístico

O histórico do turismo em Natal e os dados coletados com os agentes atuantes no desenvolvimento desta atividade econômica na Cidade demonstram que a evolução do Ciclo de vida do Destino Natal e dos produtos que o compõe encontram-se relacionados a três ações, em uma análise macro: ações estruturais, ações promocionais e planejamento participativo.

Neste aspecto, pode-se dizer que as ações estruturais, as quais tiveram o Estado como agente indutor, foram precursoras e impulsionadoras da ação coletiva. Percebe-se que as ações estruturais, foram efetuadas como estratégia de desenvolvimento regional, seguindo uma lógica de planejamento centralizado ‘de cima para baixo’ (GARRIDO, 2001).

Entretanto, a transformação proporcionada ao espaço geográfico da cidade para que o turismo se instalasse trouxe para a região mudanças na forma de estruturação das relações locais. Isto ocorre por que, como característica da própria atividade, o turismo não pode estar dissociado do ambiente em que atua. Visto na ótica sistêmica (BENI, 2001) o turismo é composto por três grandes conjuntos que estão relacionados de tal maneira que a alteração em um deles acarreta impactos para os demais.

Aliado a este fator, embora Natal apresentasse potencial paisagístico, isto não significava para este destino diferencial competitivo no mercado turístico Regional e Nacional. A pesquisa demonstrou que antes da construção da Via Costeira, não existem indícios de atividades coletivas para o desenvolvimento do turismo. No primeiro período de análise (1960-1982) não existem indícios de trabalho cooperado. Os respondentes foram questionados a esse respeito tanto no formulário, na ação estratégica 57, quanto no roteiro de entrevista nas questões 3 a 6 .

As respostas ao formulário indicaram ainda que após a implementação da Via Costeira, nos períodos B (1983-1990), C (1991-2002) e D (2003-2007), a adoção de estratégias de cooperação passa a existir. Essa constatação se deu a partir da análise de freqüência de respostas à ação estratégica 57 do formulário, com frequência de respostas de ' 3 ' (PB), '3' (PC) e '4' (PD), respectivamente. Assim, ao se observar o Gráfico 3, pode-se avaliar que o processo de crescimento da atividade passa a ocorrer concomitantemente com a ação coletiva. 
Gráfico 3 - Ciclo de vida do produto 'Litoral Urbano de Natal' versus Fases do Ciclo

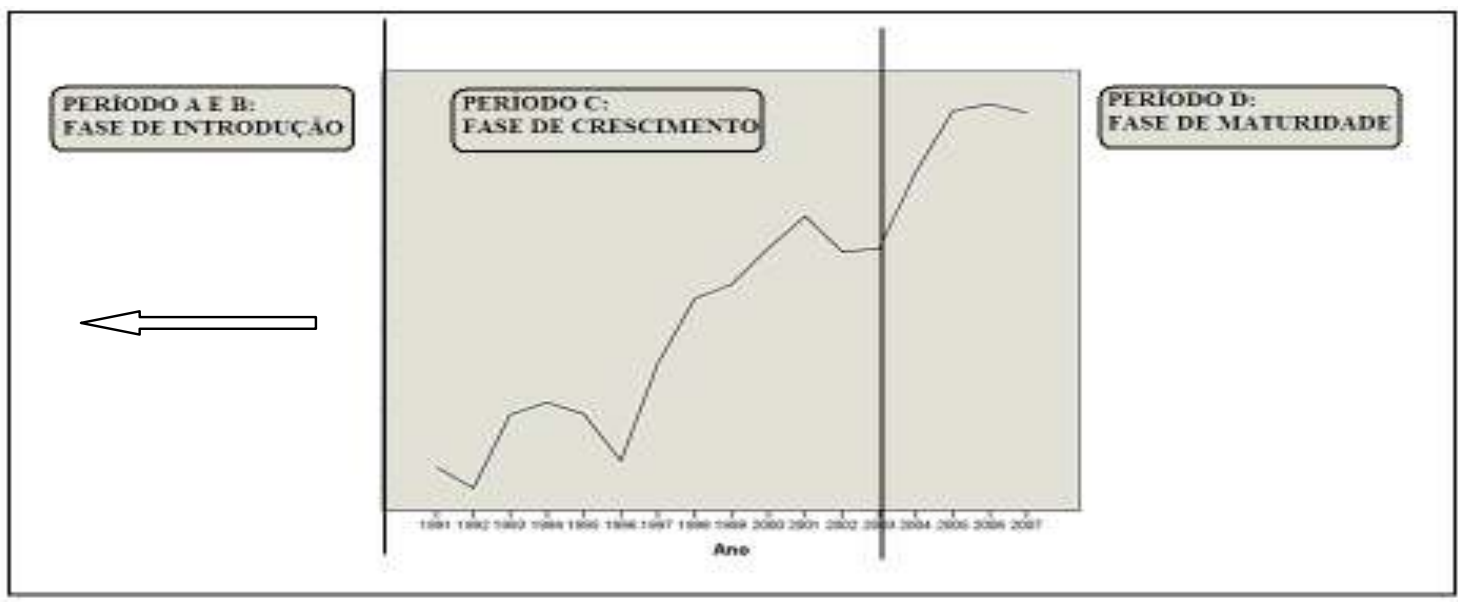

Fonte: Dados da Pesquisa, 2009

Ao se relacionar o Gráfico 3 com a existência de estratégias de cooperação identificada na freqüência de respostas dos entrevistados percebe-se que a cooperação ocorre na medida em que há o desenvolvimento do ciclo, mesmo que não se possa mensurar nesta relação a intensidade da cooperação.

Pode-se dizer, entretanto, que a cooperação esteve vinculada às principais intervenções ocorridas no destino. As ações estruturantes ocorreram durante os períodos B e C e o planejamento participativo que ganha força com a consolidação das instâncias de governança tem início no Período C e se consolida no Período D.

Segue abaixo um resumo das principais intervenções identificadas:

a. Via Costeira (1983) - proporciona a infraestrutura básica necessária à atividade turística;

b. Ações promocionais (Período B e C) - Tentativas individuais que evoluem para ações coletivas;

c. Captação de Charter Internacional (1996) - Entrada no mercado internacional. Iniciativa coletiva entre as instituições do Poder Público e Iniciativa Privada.

d. Maior participação do Terceiro Setor. (Período B).

e. Início das obras do PRODETUR/RN (1991). Criação do Pólo Costa das Dunas (2005).

f. Trabalho em Grupos Temáticos, dentro dos Conselhos (Períodos C e D).

g. Conclusão das obras de Urbanização de Ponta Negra (2001). 
h. Conselhos se consolidam como instância de governança participativa. (Períodos C e D).

No que diz respeito às ações estruturantes, pode-se afirmar que a Via Costeira impulsionou a existência do turismo e as primeiras ações em conjunto para a promoção do destino, englobando Iniciativa Privada e Poder Público. Posteriormente, a segunda ação estruturante (PRODETUR/RN) contou com a participação conjunta das três esferas Poder Público, Iniciativa Privada + Terceiro Setor.

A Figura 2 apresenta o processo de desenvolvimento do turismo no Produto 'Litoral Urbano de Natal' e a sua relação com as estratégias de cooperação adotadas.

Portanto, pode-se dizer que as ações de cooperação foram antecedidas por ações individuais e pela construção da Via Costeira. Com a realização desta primeira obra estruturante e a chegada dos primeiros hotéis, a cidade passa a existir como destino com potencial turístico. Entretanto, é a partir das ações de promoção do destino - cujo as entrevistas demonstram que têm início a partir de 1983 motivadas pela construção da Via-Costeira - que contam com estratégias de cooperação, que a Cidade de Natal passa existir como Produto Turístico. Posteriormente, com a entrada de Natal em mercados internacionais, a cidade passa a demandar uma infraestrutura que permitisse ao destino tornar-se mais competitivo.

Assim, uma nova ação estruturante é efetuada, mas com uma base de planejamento diferenciada em que a ação é individual, pois está vinculada mais uma vez ao Estado, mas o planejamento é diferenciado, conta com uma maior participação popular. Por esta razão, o PRODETUR/RN, pode ser considerado o segundo marco para a Cidade, no que concerne ao fortalecimento da ação coletiva, pois proporciona a consolidação das instâncias de governança formais. 
Figura 2 - Relação entre as ações de cooperação e o processo de desenvolvimento do turismo do produto 'Litoral Urbano de Natal'

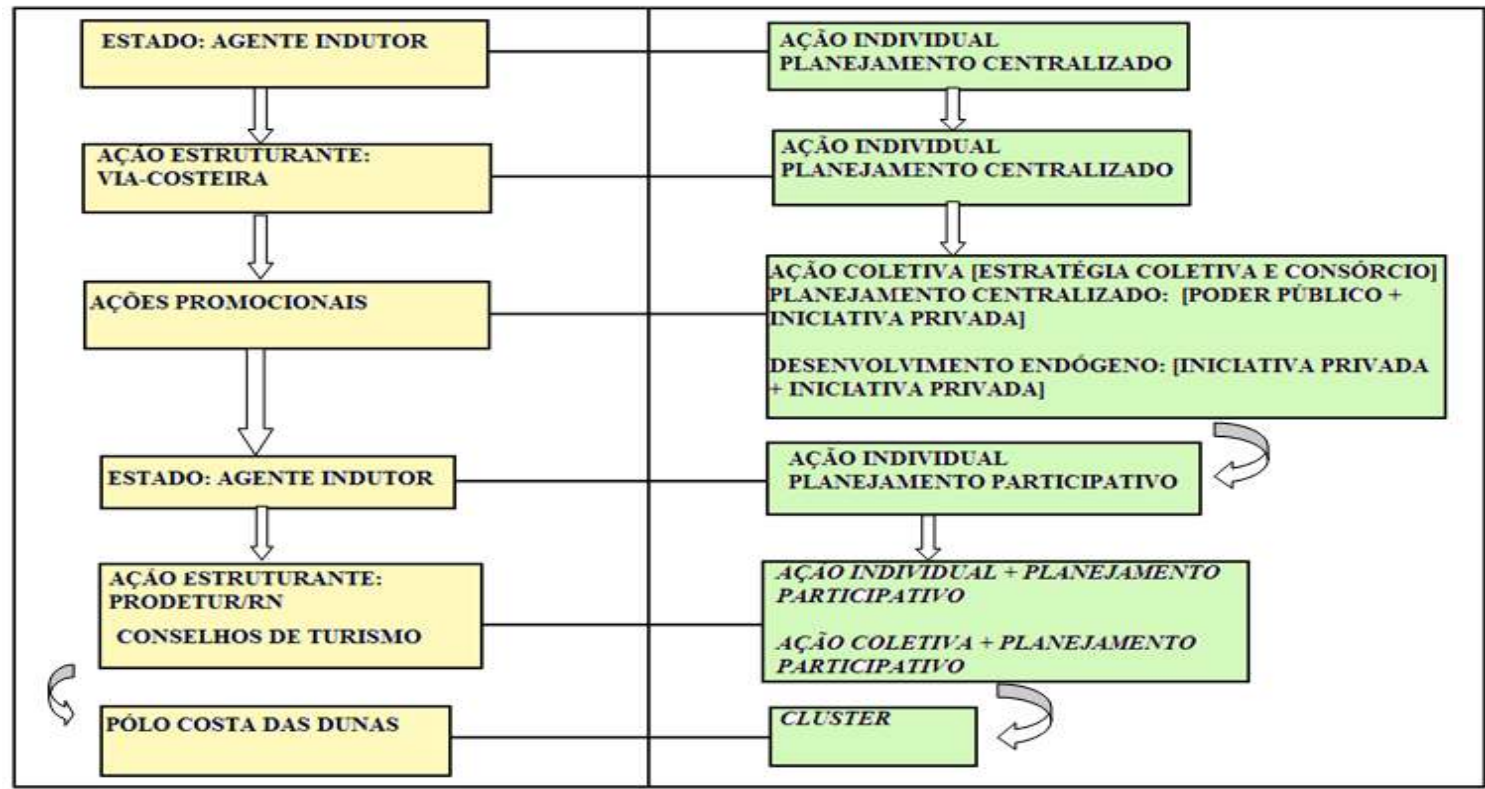

Fonte: Dados da Pesquisa, 2009

Então pode-se afirmar que as ações de cooperação ocorreram de maneira bastante pontual para ações específicas, sobretudo promocionais, antes da instituição dos conselhos. Contudo, a partir do PRODETUR/RN, com a implantação do conselho do Pólo Costa das Dunas, as ações de cooperação deixam de ser pontuais e passam a ser efetivas.

Neste sentido, cabe-se resgatar o conceito de eficiência coletiva de Schmitz (1997), na medida em que o turismo enquanto atividade econômica para a região teve o seu produto consolidado por meio das ações coletivas, embora tenha sido viabilizado inicialmente por ação individual.

As ações coletivas, que se concretizam nas estratégias de cooperação, influenciaram no ciclo de vida do produto 'Litoral Urbano de Natal', na medida em que a eficiência das ações coletivas é atingida. Essa eficiência pode ser demonstrada por meio da concretização dos projetos propostos e nos resultados alcançados. 


\section{Considerações Finais}

Este artigo é o resultado de uma pesquisa mais ampla sobre este ciclo de vida e cooperação no desenvolvimento do turismo. Um tópico de relevância abstraído da pesquisa abordou a existência de movimentos secundários ou observações atípicas durante a análise do Gráfico 1 (Relação fluxo de turistas em Natal versus período de análise) o que proporcionou o resgate de ponderações acerca da característica de sazonalidade da atividade turística além de ampliar as reflexões sobre a atividade turística e as vertentes voltadas ao pensamento sistêmico anteriormente discutidos - Sistema de Turismo e Ecologia Populacional.

A Teoria Geral dos Sistemas trouxe o entendimento da noção de sistema enquanto um complexo de elementos em interação no qual se evidenciam as relações entre os seus componentes. A aplicabilidade desta teoria foi realizada com presteza por Beni (2001) quando apresentou o Sistema de Turismo e as relações existentes entre os seus subconjuntos, que compõem o produto turístico.

Esses subconjuntos são retratados por meio de funções de planejamento, estrutura e operação do turismo, que são de responsabilidade de diferentes instituições ou organizações:

- Operação do turismo: Iniciativa privada;

- Estrutura básica necessária à atividade: Poder público; e,

- Planejamento da atividade: Poder público, cuja co-responsabilidade é também da iniciativa privada e da sociedade.

Essa compreensão, ao ser avaliada dentro da lógica da Teoria Geral dos Sistemas (BERTALANFFY,1967), permite afirmar que as populações são formadas de partes interdependentes, em que as suas relações dão coesão ao todo e cada parte está de tal forma relacionada com as demais que uma possível mudança em uma delas acarretará mudança nas outras. Neste aspecto, qualquer variação pode acarretar mudanças nas organizações que compõem a estrutura geral do produto turístico, e portanto de seu ciclo de vida.

Isso se confirma principalmente ao assumir-se que os indivíduos podem influenciar o futuro das organizações. Embora existam restrições nas suas habilidades em no processo de mudanças, no aumento das chances de sobrevivência das organizações pela competição. É 
possível considerar que tanto competição quanto cooperação coexistem em um mesmo ambiente.

Reconhecendo-se que: condições políticas, sociais e econômicas afetam a abundância e diversidade de organizações; que tais condições estão relacionadas tanto ao seu ambiente interno quanto ao seu ambiente externo; e que, o produto turístico é considerado um sistema aberto, então isto implica em dizer que alterações no ambiente externo ao produto turístico podem acarretar fortes alterações no comportamento do ciclo, e portanto, sendo também responsáveis pela existência de movimentos secundários no gráfico.

Infere-se ainda que as alterações existentes no ambiente externo podem aumentar as restrições na habilidade dos indivíduos atuarem com variações de sucesso, uma vez que eles não têm como determinar previamente quais variações serão bem sucedidas para o sucesso das organizações em função das demandas ambientais.

Portanto, a realidade apresentada permite resgatar a perspectiva de Mauad (2005), quando afirma que o conceito de ciclo de vida do produto é validado mediante as decisões estratégicas dos gestores envolvidos com os seus ambientes, podendo também ser influenciada pela estrutura de relações que compõe o sistema. Neste sentido, o sucesso ou fracasso do produto turístico pode estar relacionado à sua capacidade de lidar com os desafios que aparecem nos diferentes estágios de seu ciclo, ligados tanto ao seu ambiente interno quanto externo.

A análise das razões apresentadas pelos sujeitos entrevistados apresentou um entendimento do turismo enquanto atividade sazonal, com uma predominância de influencia de fatores externos quando comparados a fatores internos. Além disso, demonstrou que situações ocorridas em um determinado período podem não ser explicativas de um decréscimo ou ascensão do gráfico no mesmo período, pois as ações demandam algum tempo após a sua implantação para que surtam os resultados esperados. Como principais fatores predominaram questões de ordem econômica no ambiente externo e políticas no ambiente interno.

Fica claro que qualquer generalização dos fatos ou resultados apresentados torna-se inviável em função das diferenças existentes nas características de cada localidade em que pesem especialmente suas identidades culturais assim como a sua 'colonização' turística. Por esta razão as reflexões apresentadas referem-se especificamente à realidade e localidade estudada, 
o que não inviabiliza uma comparação à outras realidades que por ventura tenham sofrido intervenções semelhantes.

A pesquisa permitiu inferir ainda que as estratégias de cooperação foram adotadas para que as vantagens fossem obtidas em nível coletivo, pois estiveram voltadas para o fortalecimento do Destino Natal e dos produtos que o compõe, incluindo o seu Litoral urbano.

Pode-se afirmar que as ações de cooperação de maneira geral tiveram o Estado como indutor do processo, embora algumas ações sejam aparentemente de um processo endógeno, como é o caso do Pólo da Via Costeira.

Para responder à questão de pesquisa deste trabalho foi necessário resgatar o conceito de eficiência coletiva de Schmitz (1997). Pode-se afirmar, portanto, que as estratégias de cooperação estão relacionadas ao ciclo de vida do Produto 'Litoral Urbano de Natal' na medida em que atuam na consolidação dos projetos de desenvolvimento do turismo instituídos, quando a eficiência da ação coletiva é alcançada.

Por fim, sugere-se que as ações de cooperação venham incentivar o aumento da competitividade do produto turístico, devendo ocorrer de maneira continuada e não somente de maneira pontual. Para isso, faz-se necessária a participação conjunta do Poder Público, Iniciativa Privada e Terceiro Setor.

\section{Referências}

BAUM, J. A. C. 1999. Ecologia Organizacional. In: CLEGG, S. R.; HARDY, C.; NORD, W. R. (Org. estrangeiros); CALDAS, M.; FACHIN, R.; FISCHER, T. (org). Handbook de estudos organizacionais. v.1. São Paulo: Atlas.

BENI, M. 2001. Análise Estrutural do Turismo. 5. ed. São Paulo: SENAC.

BERTALANFFY, L. V. 1967. Teoria Geral dos Sistemas. Petrópolis: Vozes, 1973. Original do inglês.

BUTLER, R.W. 1980. The concept of a tourist area cycle of evolution: implications for management of resources. Canadian Geographer, v. 4, n. 1, p. 5-12.

CONTRACTOR, F. LORANGE, P. 1988. Why should firms cooperate? The strategy and economics basis for cooperative ventures. In: CONTRACTOR, F. LORANGE, P. (eds) Cooperative strategies in international business. Lexington, MA: Lexington Books.

GARRIDO, I. M. D. A. 2001. Modelos multiorganizacionais no turismo: cadeias, clusters e redes. 2001. Dissertação de Mestrado, Universidade Federal da Bahia.

HAIR, Jr. J. F.; ANDERSON, R. E.; TATHAM R. L.; BLACK, W. C. 2005. Análise Multivariada de Dados. 5. ed. Porto Alegre: Bookman. 
HANNAN, M., FREEMAN, J. H. 1989. Organizational ecology. Cambrige, MA: Havard University Press.

KOGUT, B. 1988. Joint ventures: Theoretical and empirical perspectives. Strategic management journal, v. 9, p. 319-332.

LINS, H. N. 2000. Clusters industriais, competitividade e desenvolvimento regional: da experiência à necessidade de promoção. Est. Econ., São Paulo, v. 30, n. 2, p. 233-265.

LORANGE, P.; ROSS, J. 1996. Alianças Estratégicas: formação, implementação e evolução. São Paulo: Atlas.

LUNDTORP, S.; WANHILL, S. 2001. The resort lifecycle Theory: generating process and estimations. Annals of tourism research, n. 28.

MAUAD, T. 2005. Índice de desenvolvimento setorial. Uma proposta para analisar o ciclo de vida dos setores. 166 f. Dissertação de Mestrado - Faculdade de Economia, Administração e Contabilidade, Universidade de São Paulo, São Paulo.

MINTZBERG, H.; AHLSTRAND, B.; LAMPEL, J. 2000. Safári de estratégia. Porto alegre: Bookman.

SCHMITZ, H. 1997. Eficiência coletiva: caminho de crescimento para a indústria de pequeno porte. Ensaios FEE, Porto Alegre, v. 18, n. 2, p.164-200.

Recebido em: 27/08/2009

Aprovado em: 12/12/2009 